\title{
When Perception Matters More than Practise - A Case Study of Foreign Language Instruction.
}

\author{
Daniel Ortins-Salerno \\ Universidade de São Paulo, Brazil
}

\begin{abstract}
This case study describes the pedagogical intervention named Processing Instruction in the teaching of syntactic structures of infinitive verbs of the English Language to adult Brazilian learner's native speakers of Portuguese. The aforementioned intervention spanned two classes of one hour each, from which one was a final exam review. The context was a so-called 'in-Company' language course over six months at the preintermediate level. From the total of 14 learners, 10 have apparently acquired the grammatical forms alluded as they were able to perceive the errors present in the items and correct them properly.
\end{abstract}

\section{Introduction}

English-language schools in Brazil have been facing a growing demand from the corporate world students to improve their teachers' performances and their pedagogical interventions. There is a growing perception that they need to learn fast and accurately. Understandably, this skilled workforce needs to communicate in English in both written and oral competences at proficient levels. Multinational corporations need highly skilled bilingual staff perfectly able to design and implement processes and policies suited for local markets. Therefore, the pressure for fast and efficient pedagogical interventions lies on the educational institutions as well on the students themselves.

The success of learning a foreign language depends on a wide range of factors such as proficiency in the native language, motivation, interaction with the teachers and classmates and a good implementation of the methodology chosen by educators, among so many other affective factors, such as anxiety and competition [1]. The present case study does not aim to analyse these elements individually, as the complexity of the phenomenon of the acquisition of a second language is beyond the limits of this text. Instead, the objective of this report is to describe the results achieved by the implementation of a pedagogical intervention for foreign language teaching named processing Instruction (PI). It was first introduced by American linguist Bill VanPatten [6] whilst researching the acquisition of Spanish as a foreign language (L2) by American native speakers of English. This model assumes that it is essential to take into account the sentence-level processing patterns of the native language (L1) and its influence in the development of the interlanguage representations of foreign language learners.

The reported experience is based on the assumptions of VanPatten [5] on the nature of form-meaning connections and the importance of considering the potential problems of word order processing intrinsic to acquiring a second language. Processing Instructions (PI) corollary asserts that if a number of conditions are met, teachers can satisfactorily alter the way in which students perceive the language input and, as a consequence, they can access more effectively their mental representations without the occasional negative interferences from their mother tongues. By establishing an overt emphasis of input activities on the teaching and learning development rather than on output-based exercises, VanPatten assumes that reading and listening play a far more relevant role in the foreign language learning process than production tasks such as drills and speaking exercises.

The present author subscribes to the effectiveness of PI in this case study describing the acquisition of infinitives of English by Brazilian learners and suggests that if there had not been the use of this particular intervention of input enhancement, the learners described here might have been be led to either an incorrect interpretation of the sentences or to a long-lasting wrong production of this kind of sentences.

In order to outline the main aspects that differentiate the pedagogical intervention, PI, from the traditional approach, usually more outputfocused, TI (Traditional Instruction), a brief description is presented below [3]:

- Native languages are utterly relevant as they present a rich source of reference for teachers to understand the processing patterns that may interfere with the learners' acquisition of L2;

- In the PI intervention, form-meaning connections are an essential part of the 
acquisition process. Therefore, learners are encouraged to link the meaning of the phrase with the corresponding grammatical form either by picture or sentence matching;

- The explicit instruction is provided in the learners' native language;

- The intervention emphasises reading and listening rather than oral and written production such as drills.

The pedagogical intervention to be reported in this case study were carried out in a company that employs the present author as its exclusive teacher of English as a foreign language to their employees who have not yet reached the proficiency level required by its headquarters. The classes were taught in groups distributed in two pairs of two, one class of five and five learners with individual classes, totalling 14 students. All learners had already studied English in one language school, at least, two times a week, as well as four years in primary and secondary school, even though in the latter condition, the lessons took place only once a week. The word order processing problems described below were observed in all learners' oral and written production or interpretation of sentences.

The reason why I set out to describe this particular type of sentence construction is down to my own experience as a teacher of English in Brazil over the period of 22 years in several different educational environments, such as schools and companies. Throughout these years, I have noticed a particular error pattern in infinitival sentences processing with the verbs 'want', 'need' and the modal phrase 'would like'. The erroneous word order processing model to be described below is, to say the least, extremely common in the learning development of pre-intermediate, intermediate and even advanced level students. Selinker and Gass [2] explain that the native language transfer of syntactic patterns may account for a wide range of errors made by unproficient users or learners of any L2. I assume that the processing errors analysed here fit this pattern of transfer described by those two authors.

As learners start to process sentences of this syntactic model, they unconsciously assume that after the verbs 'want', 'need' and 'would like', mentioned above, the following subordinate sentence will be introduced by the conjunction 'that'. I suggest that Brazilian learners tend to transfer the sentence-processing pattern of their native language, Brazilian Portuguese, and therefore, produce or mentally represent the following erroneous sentences: *'I want that you take a message" and * "I need that you take a message". (The asterisk is a graphic convention adopted by linguists to signal sentences considered ungrammatical by native speakers of a given language). The correct sentence processing in
English is "I want you to take a message" and "I need you to take a message" (subject + verb + object + infinitive), a pattern that has no resemblance to any other model of subordinate or main clauses in Brazilian or European Portuguese. Another aspect that may account for the fact that students tend to ignore certain features of the sentence and favour their own familiar language processing strategies is explained in VanPatten's first article addressing the input processing issue [6]. The author concluded that foreign language learners tend to process words with content meaning and ignore grammatical words, intrinsically without referential meaning. As an example, it is difficult, if not impossible, even for native-speakers to define a preposition, like 'from', without having to refer to its function. On the other hand, content words can be defined by means of a synonym or a paraphrase. As they faced this new sentence construction, learners might have simply ignored the object pronoun immediately after the verb and processed the sentence erroneously while interpreting (I need to take a message). However, as far as the linguistic production is concerned, whilst processing a sentence similar to those in the oral or written contexts they will tend to be influenced by the sentence pattern of their native Brazilian Portuguese, not the English one, considering that they might have not even noticed this otherwise blatant difference in the word order processing.

\section{Case study}

This case study reports a teaching experience of a five-month pre-intermediate English course of two classes per week for which the same book was used for all groups and individual learners. It is worth stressing that the grammatical topic analysed here, namely, sentences of the type SUBJECT + VERB + OBJECT + INFINITIVE, was not specifically addressed or taught in any of all the seven units of the book. It was only marginally used in a supporting dialogue of the third lesson and as a decontextualized question on the same page. As a result, that syntactic structure was not even introduced as a topic to be practised in the exercise book designed for the course pack. Throughout this period, only one student (who was part of the group of five) complained to me that he could not understand one of the sentences of the dialogue (which contained the pattern aforementioned). According to him, the sentence was so obscure that he could not even infer its meaning. As I listened to him, the other four students of the class also manifested their difficulty to understand the meaning of the clause.

Interestingly, the other nine students, who attended other classes of the same level, five of them in individual classes and also two pairs, did 
not even perceive the sentence patterns alluded until I pointed them out at the end of the class. The explanation offered by VanPatten above might account for their failing to notice the sentences.

I asked all of the fourteen students if they could understand the meaning of the clauses and although one was able to tell me the correct translation in Portuguese, the other thirteen came up with a wrong interpretation of the dialogue line. Consequently, I set out to apply the pedagogical intervention PI. In accordance with the model [6], I explained, in Portuguese, how this sentence was processed in English (Subject + Verb + object + infinitive) and that the introduction of the conjunction 'that' would not be considered acceptable by English-speaking natives as a wellformed sentence. Following this explanation, I presented images and phrases that students should match semantically. They were supposed to match ten pictures and received the feedback immediately after each item so that they could reflect upon their errors and make inferences. According to the PI intervention corollary, when exposed to these structured activities, fittingly named Structured Input (SI), students would gain the opportunity to establish form-meaning connections [5]. Consequently, as learners read a sentence in L2, their attentional system is conducted to form a connection between the event portrayed in the image and the grammatical form needed to convey this meaning. Below there is an example of one of the trials.

- Listen to your teacher and circle the correct option.

Teacher: "I need the chef to be more attentive".

a)

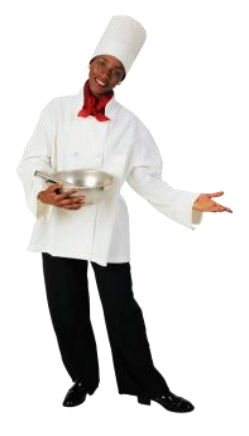

b)

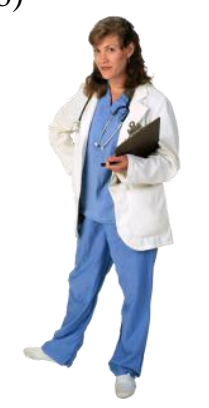

Students than circled the correct options in their brochures prepared beforehand by me. Note that they were not encouraged to speak or to repeat any set of drills. In contrast, they were only supposed to match meaning and form. After having been explicitly instructed that the English sentence processing differed from Portuguese, they were free to direct their attention to the connection.

At the end of six months, all students had a review lesson that covered the contents of preintermediate level seven units. That was the second time I taught them the infinitival sentences. Although I went over this grammatical point and reminded them of the PI intervention with the Structured Input activities that they had nearly two months before, I did not repeat the SI trials with the picture matching. Interestingly, nearly one week later, ten students were able to get the questions related the infinitival sentences right at the test. This specific session of the final exam consisted of two sentences to be corrected where they were supposed to write the correct word order next to each item. Therefore, they were meant to understand the sentences and correct them according to what they had been instructed by means of the structured input activities.

\section{Discussion}

The experience points out the importance of enhancing learners' perception to the relevant language input. Moreover, it also stresses how crucial it is to refer to learners' native languages in order to understand L1 patterns conflicting with L2 properties, especially those that seem confusing to be noticed and understood. The cognitive mechanism of transfer is an important influence in the development of the acquisition of a second language. Therefore, the pedagogical intervention PI seems to be effective because it addresses the L2 potential sentence processing problems as it always refers to learners' native languages syntactic patterns.

From this particular case study as well as from the experience I had whilst carrying out my master's degree research on the acquisition of English adjectives by Brazilian learners, it seemed that, by adopting a pedagogical intervention that discourages the contrast between the processing of L1 and L2, teachers may miss the opportunity to raise learners' awareness to potential processing problems resulting from transfer. As far as perception is concerned, learners may fail to perceive that the structures of L1 and L2 differ. Similarly, Schmidt [4] stresses that the awareness of particular properties of the L2 is absolutely essential for learners to understand sentences correctly. Moreover, it also drives their attention to correct form-meaning connections. Failing to do so may lead them to fossilize, so to speak, the wrong 
pattern in their development. (According to Selinker [7], this phenomenon refers to any erroneous linguistic material that learners will tend to keep in their linguistic production, no matter how much instruction they might have received on the proper form to be used instead.)

Consequently, this experience may suggest that pedagogical interventions that seriously pursue to take the learner's perspective into account and drive their perception towards form-meaning connections may contribute to the development of more effective acquisition of grammatical forms usually unnoticed or hardly ever learned. In this report, it is suggested that the approach adopted, Processing Instruction, was effective in teaching the alluded grammatical form in spite of the reduced number of classes dedicated to instruct the classes in the particular grammatical form alluded. It is noteworthy that the encouraging results in the acquisition of this grammatical form justifies a larger experimental study including a thorough statistical analysis comparing groups and different teachers utilizing both Traditional Instruction (TI) and Processing Instruction (PI) interventions.

\section{References}

[1] Ellis, R., Second Language Acquisition, 2nd edition, Oxford University Press, Oxford, 2012.

[2] Gass, S. and Selinker, L., Second Language Acquisition: An Introductory Course, 2nd ed., Johns Benjamin, Amsterdam, 2001.

[3] Ortins-Salerno, D., "Processing Instruction and the Learning of Adjectives by Brazilian Learners", Literacy Information and Computer Education Journal, vol. 5, issue: 3: 2014, pp. 1588-1596.

[4] R. Schmidt, "Psychological Mechanisms Underlying Second Language Fluency", Studies in Second Language Acquisition, vol. 14, Cambridge University Press, Cambridge, 1992, pp. 357-385.

[5] B. VanPatten, "Processing instruction: an update", Language Learning, vol. 52, Wiley Online Library, Hoboken, NJ, 2002, pp. 755-804.

[6] VanPatten B. and Cadierno, "Input Processing and Second Language Acquisition: A Role for Instruction", The Modern Language Journal, vol. 77, issue: 1: Wiley Online Library, Hoboken, NJ, 1993, pp. 45-57.

[7] Selinker, L., Redescovering Interlanguage, Longman, New York, 1992. 